University of Nebraska - Lincoln

DigitalCommons@University of Nebraska - Lincoln

U.S. Department of Veterans Affairs Staff

Publications

U.S. Department of Veterans Affairs

2003

\title{
Analysis of Conserved Non-rRNA Genes of Tropheryma whipplei
}

Matthias Maiwald

Stanford University School of Medicine, maiwald@cmgm.stanford.edu

Paul W. Lepp

Stanford University School of Medicine, paul.lepp@minotstateu.edu

David A. Relman

Stanford University School of Medicine, relman@stanford.edu

Follow this and additional works at: https://digitalcommons.unl.edu/veterans

Maiwald, Matthias; Lepp, Paul W.; and Relman, David A., "Analysis of Conserved Non-rRNA Genes of Tropheryma whipplei" (2003). U.S. Department of Veterans Affairs Staff Publications. 20.

https://digitalcommons.unl.edu/veterans/20

This Article is brought to you for free and open access by the U.S. Department of Veterans Affairs at DigitalCommons@University of Nebraska - Lincoln. It has been accepted for inclusion in U.S. Department of Veterans Affairs Staff Publications by an authorized administrator of DigitalCommons@University of Nebraska - Lincoln. 


\title{
Analysis of Conserved Non-rRNA Genes of Tropheryma whipplei
}

\author{
Matthias Maiwald ${ }^{1}$, Paul W. Lepp ${ }^{1,2}$, and David A. Relman ${ }^{1,2,3}$ \\ Departments of Microbiology and Immunology ${ }^{1}$ and of Medicine ${ }^{2}$, Stanford University School of Medicine, Stanford, California, USA \\ Veterans Affairs Palo Alto Health Care System, Palo Alto, California, USA ${ }^{3}$
}

Received: January 7, 2003

\begin{abstract}
Summary
The causative agent of Whipple's disease, Tropheryma whipplei, is a slow-growing bacterium that remains poorly-understood. Genetic characterization of this organism has relied heavily upon rRNA sequence analysis. Pending completion of a complete genome sequencing effort, we have characterized several conserved non-rRNA genes from T. whipplei directly from infected tissue using broad-range PCR and a genome-walking strategy. Our goals were to evaluate its phylogenetic relationships, and to find ways to expand the strain typing scheme, based on rDNA sequence comparisons. The genes coding for the ATP synthase beta subunit $(a t p D)$, elongation factor Tu $(t u f)$, heat shock protein GroEL (groEL), beta subunit of DNA-dependent RNA polymerase $(r p o B)$, and RNase P RNA $(r n p B)$ were analyzed, as well as the regions upstream and downstream of the rRNA operon. Phylogenetic analyses with all nonrRNA marker molecules consistently placed T. whipplei within the class, Actinobacteria. The arrangement of genes in the atpD and $r p o B$ chromosomal regions was also consistent with other actinomycete genomes. Tandem sequence repeats were found upstream and downstream of the rRNA operon, and downstream of the groEL gene. These chromosomal sites and the 16S-23S rRNA intergenic spacer regions were examined in the specimens of 11 patients, and a unique combination of tandem repeat numbers and spacer polymorphisms was found in each patient. These data provide the basis for a more discriminatory typing method for T. whipplei.
\end{abstract}

Key words: Tropheryma - Whipple's disease - phylogeny - genome walking - strain typing

\section{Introduction}

Whipple's disease is a systemic illness characterized by the presence of monomorphic bacteria and a macrophage infiltrate in affected organs and tissues. Since the first description of this disease in 1907, many attempts have been undertaken to cultivate this bacterium, and many have failed. In 1991-92, the Whipple's disease bacterium was characterized based on its $16 \mathrm{~S}$ rRNA sequence, using a broad range polymerase chain reaction (PCR) approach and was shown to be a member of the Actinobacteria $[32,48]$. Co-cultivation of the bacterium in the presence of a human fibroblast cell line was reported in 2000 [30].

Due to the long-standing absence of purified and culturable bacterial cells, little information has been available regarding the phenotypic and genotypic characteristics of the Whipple bacillus, Tropheryma whipplei. Many aspects of its natural ecology, routes of transmission, and pathogenicity are unclear. A detailed assessment of its phylogeny based on $16 \mathrm{~S}$ rDNA sequence analysis revealed an intermediate position between a group of actinomycetes with group B peptidoglycan and the family Cellulomonadaceae [26]. The $16 \mathrm{~S}-23 \mathrm{~S}$ ribosomal intergenic spacer exhibits limited sequence variability, with seven types so far described, and is now the basis for a strain typing scheme $[8,15,26,28]$. The overall organization of the T. whipplei rRNA operon is in general accordance with that of the other actinomycetes, but some features, such as a $23 \mathrm{~S}$ rRNA insertion sequence and predicted rRNA secondary structures are quite dissimilar to the corresponding features of other actinomycetes [28].

Beyond the rRNA operon, only scant information has been available regarding genes, genetic organization, and predicted gene products. A $620 \mathrm{bp}$ fragment of the groEL heat shock protein gene has been determined and employed in a diagnostic PCR test [29]. In addition, a com- 
plete $r p o B$ sequence (beta subunit of DNA-dependent RNA polymerase) was obtained from a laboratory-propagated isolate of T. whipplei [6], and used for the same purpose. A phylogenetic analysis of the RpoB protein sequence provided further evidence for a relationship of $T$. whipple $i$ with the actinobacteria.

In order to verify this phylogenetic assignment of $T$. whipplei and enhance strain discrimination capabilities, we targeted conserved genes using degenerate broadrange PCR and combined this with a "genome walking" strategy. Our targets included the genes coding for ATP synthase beta subunit $(a t p D)$, elongation factor Tu $(t u f)$, heat shock protein GroEL ( $g r o E L$ ), and the beta subunit of DNA-dependent RNA polymerase $(r p o B)$, and the RNase P RNA $(r n p B)$ gene. The genome walking strategy was also applied to the regions upstream and downstream of the rRNA operon [28]. Despite their conservation, these genes offer reliable phylogenetic information, and the possibility of useful sequence polymorphisms. Examination of these chromosomal regions also provides an early, but limited glimpse at the genome organization of this enigmatic bacterium.

\section{Materials and Methods}

\section{Patient specimens}

A paraffin-embedded intestinal biopsy specimen from a patient with "classical" intestinal Whipple's disease was used to amplify and assemble all of the chromosomal regions in this study. This specimen had been obtained from a 72-year-old female with a diagnosis established in 1999 based on standard histopathology criteria, and prior to antibiotic treatment. A group of specimens was used to confirm the T. whipplei sequence data obtained in this study: 3 intestinal endoscopic biopsy and 3 cerebrospinal fluid (CSF) specimens from patients with Whipple's disease confirmed by both histology and PCR. In addition, a group of 3 intestinal biopsy and 3 CSF specimens from patients who had no evidence of Whipple's disease by histology or PCR was used to establish the specificity of these findings. Ten additional specimens ( 5 intestinal biopsies and 5 CSF samples) from patients with confirmed Whipple's disease provided bacterial genomic template for analysis of variable sequence sites identified in this study. DNA from the specimens was extracted as described previously $[45,46]$.
PCR

Several genes that are conserved across a wide range of organisms were selected as targets for consensus PCR: ATP synthase beta subunit $(a t p D)$, elongation factor $\mathrm{Tu}(t u f)$, heat shock protein GroEL (groEL), beta subunit of RNA polymerase $(r p o B)$, and RNase P RNA $(r n p B)$. Sequences for each of these genes from a representative set of bacteria were aligned. Degenerate broad-range primers (Table 1) were designed and used in an initial series of PCR experiments. PCR products were cloned into the TA vector system (Invitrogen, Palo Alto, CA, USA), sequenced using standard reagents and equipment (ABI, Foster City, CA, USA), and analyzed using the BLAST software package (http://www.ncbi.nlm.nih.gov/BLAST/). Sequences with similarity to those of other actinomycetes were incorporated into the alignments, and specific internal primers (Table 1) were constructed. The primers were then tested in PCRs with the 6 Whipple's disease and 6 negative control specimens, in order to confirm that the novel sequences were associated with T. whipplei.

\section{Genome "walking"}

To examine sequence adjacent to regions bounded by the conserved priming sites, specific primers were designed such that their orientation was facing outwards. These primers were initially used in combination with primers designed from more distant conserved sequence regions. This process was repeated until no more adjacent sequence with sufficient conservation could be identified within the aligned data set. As a final step, the newly acquired chromosomal sequence regions were then further extended using restriction site PCR [36]. A second confirmation procedure was then performed to assess the specificity of the sequences at the ends of the chromosomal regions: specific primers facing inwards from the ends of the newly acquired sequence were combined with the previous set of specific outward-facing primers, and tested in PCRs with the 6 Whipple's disease and 6 negative control specimens. The overall PCR strategy is shown in Figure 1. Examination of polymorphic sites in other Whipple's disease specimens was accomplished using additional sets of primers (Table 1).

\section{Sequence analysis}

Alignments and phylogenetic analyses were performed using the ARB program package [39]. Clustal W (Genetics Computing Group, Wisconsin) and Iteralign ([1]; http://giotto.stanford.edu/ luciano/iteralign.html) were used for auxiliary protein sequence alignments. A prealigned set of type A RNase P RNA sequences was downloaded from the RNase P RNA database [3]; http://www.mbio.ncsu.edu/RNaseP/home.html) and imported into ARB. Phylogenetic trees were based on the predicted pro-

(1) Broad-range PCA with degenerate primers

(2) Confirmatory PCR with specific primers

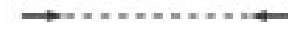

(3) Extension with outer broad-range primers

(4) Genome-walking PCA

5) Genome-walking PCR: additional steps,

depending on gene size (not depicted)

(6) Final confirmatory PCP

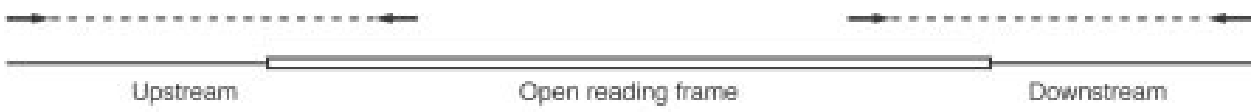

Fig. 1. General scheme of the PCR strategy used to acquire sequences of conserved genes and adjacent regions. The number of steps required to acquire each individual chromosomal region varied, depending on length and the availability of sites for outer degenerate broad-range primers. 
Table 1. Key primers used for the acquisition of novel sequences from T. whipplei and primers for sequence-based typing of different strains.

\begin{tabular}{lll}
\hline Gene, Primer & Sequence & Comments $^{\mathrm{a}}$ \\
\hline $\begin{array}{l}\text { atpD } \\
\text { atp508f }\end{array}$ & & \\
atp701r & $5^{\prime}$-ttyggyggygciggigtiggyaarac & Initial broad-range \\
atp544f & $5^{\prime}$-ggctcrtycatytgiccraaiacca & Initial broad-range \\
atp653r & $5^{\prime}$-caggaaatgatacaaagagtg & Specific, initial confirmation \\
atp79f & $5^{\prime}$-gcatcctgcatcycgcgaatc & Specific, initial confirmation \\
atp1205r & $5^{\prime}$-aygggiscigtcgtygacgtigaitt & Secondary broad-range \\
& $5^{\prime}$-atrcciargatigcratratrtc & Secondary broad-range \\
tuf & & \\
eftu46f & & \\
eftu671r & $5^{\prime}$-ggsaccatyggicayrtygacca & Initial broad-range \\
eftu114f & $5^{\prime}$-ccggtratigwgaagacgtcctc & Initial broad-range \\
eftu571r & $5^{\prime}$-gaggcttccttcgaatacg & Specific, initial confirmation \\
eftu1077r & $5^{\prime}$-taaccgcatcgcccactttg & Specific, initial confirmation \\
& $5^{\prime}$-ggygttgtcrcciggcatsaccat & Secondary broad-range
\end{tabular}

groEL

$\begin{array}{ll}\text { whipp-frw1 } & \text { 5'-tgacgggaccacaacatctg } \\ \text { whipp-rev } & \text { 5'-acatcttcagcaatgataagaagtt } \\ \text { gro64f } & \text { 5'-ctsgcsgayrcsgtiaaggtsac } \\ \text { gro1492r } & \text { 5'-gggtsaccttsaccgggtc } \\ \text { gro1390f } & \text { 5'-ggtaaggtatcttcttacctc } \\ \text { gro+416r } & \text { 5'-aataccgaaaatatggagggtag }\end{array}$

$r p o B$

rpob1303f

rpob1844r

rpob1497f

rpob1679r

rpob470f

rpob2674r

rpob3221r

$r n p B$

rnsp59f

rnsp347r

rnsp114f

rnsp308r

5 -cagctgwsicarttcatggaccaramcaaycc

5 -gcytgicgytgcatgttigmicccat

$5^{\prime}$-tttagcgtgctattccagggtg

$5^{\prime}$-agaacacgctcatcaacaaacg

5 -cggaattcctyccnhtnatgacnga

5 -cggaattccccyttrttnccrtgncgncengc

5 -'cgggatccegccanmmytccat

rRNA operon upstream region
tw70r
op-432f
5 '-caaggaccgacaggacgaacc
$5^{\prime}$-atggaccaataccaaaggaac

rRNA operon downstream region
tw5670f
5 -cctcaaacccaagcttattcgcc
op+276r
5 -caaaagaatatctataagcac

Restriction-site PCR
NheI-RSO
PstI-RSO
5 -aatacgactcactataggnnnnnnnnnngctagc
MscI-RSO
$5^{\prime}$-a a
5 '-aatacgactcactataggnnnnnnnnnntggcca

Initial specific [29]

Initial specific [29]

Secondary broad-range

Secondary broad-range

Sequence-based typing

Sequence-based typing

Initial broad-range

Initial broad-range

Specific, initial confirmation

Specific, initial confirmation

Secondary broad-range

Secondary broad-range

Tertiary broad-range

Initial broad-range [9]

Initial broad-range [9]

Specific, initial confirmation

Specific, initial confirmation

Sequence-based typing

Sequence-based typing

Sequence-based typing

Sequence-based typing

Restriction-site oligonucleotide

Restriction-site oligonucleotide

Restriction-site oligonucleotide

${ }^{\prime}$ Numbering of the primers for atpD, tuf, groEL, $r p o B$, and $r m p B$ is based on the numbering in the corresponding genes of $M y c o b a c$ terium tuberculosis, as a reference.

' Primers were designed in this study, except the 5' portions of restriction-site oligonucleotides [36] and where other references are given. 
Table 2. Overview of the codon usage and total G+C content of the concatenated genes atpD, tuf, groEL, and rpoB.

\begin{tabular}{lllc}
\hline Organism & Total G+C content & Third position G+C content & No. of unused codons (of 64) \\
\hline T. whipplei & $50 \%$ & $48 \%$ & 1 (stop TGA) \\
M. tuberculosis & $64 \%$ & $86 \%$ & 3 (Arg) \\
M. leprae & $60 \%$ & $77 \%$ & 13 (2 stop) \\
Strep. coelicolor & $66 \%$ & $94 \%$ & 7 \\
Staph. aureus & $38 \%$ & $21 \%$ & 4 \\
B. subtilis & $46 \%$ & $38 \%$ & 7 \\
E. coli & $53 \%$ & $57 \%$ & \\
\hline
\end{tabular}

tein sequences, and for RNase P RNA, on DNA sequences, and were calculated using the Neighbor-Joining, Maximum Parsimony, and Maximum Likelihood algorithms [7]. Tree topologies were evaluated by bootstrap analysis with 100 re-samplings.

Sequences at the NCBI microbial genomes website (http://www.ncbi.nlm.nih.gov/PMGifs/Genomes/micr.html) and a set of Streptomyces coelicolor cosmids [31] were used for comparisons of T. whipplei gene arrangements with those of other microbial genomes. Sequences were tested for open reading frames (ORFs) using the ORF finder at the NCBI website, the Glimmer program (TIGR, The Institute for Genomic Research, Rockville, MD), and the Artemis annotation tool (Sanger Institute, Cambridge, UK).

The following additional sequence analysis resources were used: for codon usage and nucleotide composition, Codonfrequency and Composition (GCG package); for protein family assignment, Pfam (http://pfam.wustl.edu); for transmembrane protein prediction, TMpred (http://www.ch.embnet.org/software/TMPRED_form.html); for signal peptide prediction, SignalP (http://www.cbs.dtu.dk/services/SignalP); to search for blocks of conserved sequences, Block Searcher ([12]; http://blocks.fhcrc.org/blocks/blocks_search.html), to search for tRNAs, tRNAscan SE (http://www.genetics.wustl.edu/eddy/ tRNAscan-SE); and to search for repeat regions, Tandem Repeats Finder (http://c3.biomath.mssm.edu/trf.html).

\section{Nucleotide sequence data deposition}

The sequences of the chromosomal regions determined in this work have been deposited in the GenBank/EMBL databases under accession nos. AF483648-AF483654. The secondary structure of RNase P RNA was determined by James W. Brown (North Carolina State University) and was deposited at the RNase P RNA website (http://www.mbio.ncsu.edu/RNaseP/home.html).

\section{Results and Discussion}

\section{Assembled sequences}

Multiple locus genome sequence analysis has significantly enhanced our understanding of the evolution and functional capabilities of fastidious microorganisms. $T$. whipplei is a pre-eminent example of a microorganism that has resisted characterization because of its recalcitrance to cultivation. Consensus PCR and genome-walking techniques provide an opportunity for genetic characterization of T. whipplei directly from a relevant infected site, i.e. the diseased human intestinal lamina propria. The recent published reports of $T$. whipplei laboratory cultivation describe bacterial generation times as long as 18 days. Our approach for genetic characterization avoids mutations that might arise during prolonged laboratory propagation and become fixed as a result of laboratory adaptation.

DNA sequences from each of 7 unlinked chromosomal loci were assembled based on PCR products amplified from an intestinal biopsy specimen of a patient with Whipple's disease. These chromosomal regions encompass the ATP synthase (atpD) gene (assembly size 2392 bp), elongation factor Tu (tuf) gene (assembly size 1865 $\mathrm{bp}$ ), heat shock protein GroEL (groEL) gene (assembly size $2551 \mathrm{bp})$, DNA dependent RNA polymerase $(r p o B)$ gene (assembly size $3815 \mathrm{bp})$, RNase P RNA ( $r p \mathrm{~B})$ gene (assembly size $568 \mathrm{bp}$ ), and the regions upstream $(802$ bp) and downstream (1200 bp) of the rRNA operon. The newly-determined sequences comprise $13,193 \mathrm{bp}$ with a $\mathrm{G}+\mathrm{C}$ content of $49 \%$ (individual regions: $46.1 \%, 50.0 \%$, $49.2 \%, 50.2 \%, 51.8 \%, 47.1 \%, 49.7 \%$, respectively), which is lower than the estimated $\mathrm{G}+\mathrm{C}$ content of a cultivated isolate $(59 \%)$ using HPLC [22], and in keeping with a figure of $46.3 \%$ from a $T$. whipplei full genome sequencing project (J. Parkhill, unpublished data; http://www.sanger.ac.uk/Projects/T_whippelii/). tRNA genes were not identified. The 16S-23S rRNA intergenic spacer sequence from our index patient was type $2[15$, 28].

To assess whether the amplified and assembled sequences were specific to Whipple's disease tissues and hence, to T. whipplei, PCRs were performed with primers designed from specific sequences at the center of the assembled regions and primers from the ends (Table 1, Fig. 1). All PCRs with these specific primer pairs yielded products of the expected size from all 6 Whipple's disease tissues and from none of the six non-Whipple's disease tissues.

T. whipplei codon usage and chromosomal G+C content was compared to a group of well-studied actinobacteria and other bacteria using a sequence data set from Mycobacterium tuberculosis, Mycobacterium leprae, S. coelicolor, Staphylococcus aureus, Bacillus subtilis, and Escherichia coli. The data set consisted of concatenated sequences for atpD, tuf, groEL, and rpoB (7716-8244 bp in the different species). The results are shown in Table 2. While the third-position $\mathrm{G}+\mathrm{C}$ content generally reflected overall $\mathrm{G}+\mathrm{C}$ content, the small number (i.e., one) of unused codons in the T. whipplei sequence set is unusual. The evenness of codon usage (or degree of bias) in an organism may be correlated with its growth rate [19]. The relative level of expression of a gene is also thought to be 
a determinant of the degree of codon bias displayed by that gene. All four genes in our analysis are among the top 20 predicted most highly expressed genes based on codon usage, as determined in an analysis of the genomes of four fast-growing bacteria [19]. Thus, the relatively unbiased use of codons in these T. whipplei genes supports the observation from in vitro cultivation experiments that this is a very slowly growing organism [30].

\section{ATPase gene region}

The ATPase chromosomal region (2392 bp) contains an ORF that is predicted to encode an $\mathrm{F}_{1} \mathrm{~F}_{0}$ type ATP synthase beta subunit (atpD gene) with 474 predicted amino acids (aa) and a calculated molecular mass of $52 \mathrm{kDa}$. The AtpD putative protein sequence displays typical conserved amino acid signatures for this family of proteins: Walker A (P-loop), GGAGVGKTV; Walker B, LLFID; and the DELSEED sequence ([35, 47]; Karlheinz Altendorf, University of Osnabrück, Germany, personal communication). Upstream of atpD, there is a $485 \mathrm{bp}$ (160 aa) ORF that is predicted to encode the C-terminal portion of the ATP synthase gamma subunit $(\operatorname{atp} G)$, and downstream of atpD, there is a complete ORF (285 bp, 94 aa) encoding an ATP synthase epsilon subunit (atpC).

In bacteria which have $\mathrm{F}_{1} \mathrm{~F}_{0}$ type ATP synthases, the genes for the subunits of this complex are usually arranged in an operon and in the order atpIBEFHAGDC [13]. In accordance with this pattern, the characterized genes from the atp operon of T. whipplei are organized in the order atpGDC. The putative epsilon subunit (AtpC) of T. whipplei (94aa) is significantly shorter than the epsilon subunits of related actinobacteria, M. tuberculosis (121 aa), M. leprae (121 aa), S. coelicolor (124 aa), as well as many other bacteria for which this subunit has been characterized. A Block search [12] identified only 1 of 2 conserved AtpD sequence motif blocks. An epsilon subunit (86 aa) of similarly unusual size is found in Caulobacter crescentus, and in like fashion contains only 1 of 2 sequence blocks. The biological significance of the apparently truncated T. whipplei and C. crescentus AtpC proteins remains unclear.

A putative ORF downstream of atpC in the T. whipblei genome displayed little similarity with ORFs at the same location in the genomes of other actinobacteria, although all showed evidence for a signal sequence and a transmembrane region. The Iteralign program [1] recognized a highly similar region in the sequences of T. whipblei (ALYIIGLFAF), S. coelicolor and S. lividans (both AVVVIGLFVF), starting at residue 15 of all three proteins. This suggests that these predicted products encoded by these ORFs may be analogs, but it remains unclear if their gene products are functionally related to the ATP synthases.

\section{Elongation factor-Tu gene region}

The elongation factor Tu chromosomal region $(1865$ bp) contains an ORF predicted to encode a typical Tuf protein (397 aa, $43.5 \mathrm{kDa}$ ). This Tuf sequence contains a conserved P-loop motif: IGHVDHGKTT [35]. Within the $151 \mathrm{bp}$ upstream and $520 \mathrm{bp}$ downstream of $t u f$, no ORF was found that yielded a hit with an E-value better than $10^{-1}$ in Blast searches.

Bacterial tuf genes are commonly located within an rpsL operon, containing the genes for the ribosomal proteins S12 (rpsL) and S7 (rpsG), elongation factor G (fus), and elongation factor Tu $(t u f)$, in that order. Many proteobacteria (e.g., E. coli) have two almost identical tuf alleles, both expressed at high levels, of which only $t u f A$ is located in the rpsL operon [16, 38]. Most low $\mathrm{G}+\mathrm{C}$ Gram-positive bacteria and actinobacteria have one $t u f$ allele, which is located downstream of fus in the rpsL operon. For comparison, fus-tuf intergenic regions range from 109-362 bp in M. tuberculosis, M. leprae, S. coelicolor, and C. glutamicum. Two streptomycetes are exceptions to the single $t u f$ allele pattern within the actinobacteria; Streptomyces ramocissimus has three tuf alleles (tuf1, tuf2, tuf3), and S. coelicolor has two (tuf1, tuf3). The tuf2 and $t u f 3$ alleles are not expressed at detectable levels, nor located in the rpsL operon, and tuf3 is quite dissimilar (63-65\% aa identities) to the other alleles [42, 44]. However, apart from the streptomycetes, no other organism within the Actinobacteria has been found so far with more than one tuf allele. A preliminary analysis of the T. whipplei genome reveals only one tuf gene; the rest of the rpsL operon is found at an unlinked locus (http://www.sanger.ac.uk/Projects/T_whippelii/).

\section{GroEL gene region}

The GroEL chromosomal region (2551 bp) contains an ORF predicted to encode a typical GroEL heat shock protein $(540$ aa, $57 \mathrm{kDa})$. Within the $512 \mathrm{bp}$ upstream and $416 \mathrm{bp}$ downstream of groEL, no ORF was found that yielded a Blast search hit with an E-value better than $10^{-2}$; nevertheless, one potential ORF (336 bp) was strongly predicted by the Glimmer program downstream of groEL (score 99 of 99). There were two copies of a 21 bp sequence repeat (TTTATGTCATTCTCTTGCAGA) within this potential downstream ORF. CIRCE regulatory elements are commonly found upstream of groES or groEL genes in many bacteria [10], but none was not found in the T. whipplei chromosomal region.

Bacterial groEL genes are often located in groESL operons, where they are located downstream of groES. Those actinobacteria for which information is available, have two groEL genes, one of which (groEL1) is located downstream of groES (C. diphtheriae, M. tuberculosis, M. leprae, S. coelicolor: 12-139 bp downstream), while the other (groEL2) is located elsewhere on the genome [4, $5,31,34]$. No groES gene was identified within 512 bp upstream of the T. whipplei groEL. Furthermore, the T. whipplei predicted GroEL protein sequence contains a Cterminal MDF amino acid sequence. Similar glycine-methionine-rich motifs are found in actinobacteria GroEL2 proteins, whereas actinobacteria GroEL1 proteins contain histidine-rich C-terminal sequences [2, 34]. These data suggest that this T. whipplei groEL gene is a groEL2 allele. Preliminary analysis of the complete T. whipplei 
genome sequence indicates that this is the only T. whipplei groEL allele and confirms that it is not physically linked to the groES locus (unpublished data; http://www.sanger.ac.uk/Projects/T_whippelii/).

\section{RpoB gene region}

The RpoB chromosomal region (3815 bp) contains an ORF predicted to encode a typical beta subunit of a DNA-dependent RNA polymerase (1157 aa, $128 \mathrm{kDa})$. The sequence of this contig is almost identical to a previously-determined $r p o B$ sequence from a cultivated $T$. whipplei isolate (Drancourt et al., 2001). However, in the currently reported analysis a GTG start codon was chosen (178 bp downstream of the previously proposed start), based on an inspection of actinobacteria RpoB alignments. Within $27 \mathrm{bp}$ of the end of the $r p o B$ ORF there is the beginning of a predicted gene encoding the beta' subunit of RNA polymerase $(r p o C)$. The RNA polymerase genes $r p o B$ and $r p o C$ occur in a tandem arrangement in the majority of bacterial genomes, as is the case with the T. whipplei genome.

\section{RNaseP RNA gene region}

A complete gene $(r m p B, 351 \mathrm{bp})$ for the T. whipplei RNase P RNA was recovered and analyzed. The predicted secondary structure of the RNA molecule was that of a typical type A RNase P RNA, but without an additional bulge in helix L15 that is present in most other actinobacteria [9]. The predicted T. whipplei RNase P RNA structure is available at the RNase P RNA website (http://www.mbio.ncsu.edu/RNaseP/home.html).

\section{rRNA operon region}

Using restriction site PCR (Sarkar et al., 1993), 455 bp of additional sequence was characterized upstream of the previously-sequenced rRNA operon [28]. Two copies of a 14-bp imperfect tandem repeat (AACTGWTACTGAGT) were identified in this region, but no predicted gene. As a point of comparison, the genomes of M. tuberculosis and $M$. leprae contain a murA gene (UDP-N-acetylglucosamine enolpyruvyl transferase) within 296 and 308 bp upstream of their single-copy $16 \mathrm{~S}$ rRNA gene, while S. coelicolor, with 6 rRNA operons, has a different complement of genes upstream of its rRNA operons. Downstream of the T. whipplei rRNA operon, $539 \mathrm{bp}$ of new sequence was acquired, thereby extending chromosomal characterization 1033 bp beyond the end of the T. whipplei $5 \mathrm{~S}$ rDNA. The absence of sequence variability or ambiguity in these amplified products and extended chromosomal regions flanking the T. whipplei rRNA operon is in keeping with preliminary findings from the T. whipplei genome project that there is only one copy of an rRNA operon in this genome (http://www.sanger.ac.uk/ Projects/T_whippelii/). Two different repeat regions were identified within the downstream region, one consisting of 11 repeated Gs, and the other consisting of 6 tandem copies of a 9 bp repeat (GTTCTAGTA). These variable number tandem repeat loci provide the basis for a new potentially useful T. whipplei strain typing scheme (see below).

\section{T. whipplei phylogeny}

All of the molecules characterized in this study (AtpD, Tuf, GroEL, RpoB, and $r n p B$ ) have previously been used as phylogenetic markers [9, 21, 23, 33, 43, 49]. The use of non-rRNA markers has been proposed for independent assessment of $16 \mathrm{~S}$ rRNA-based relationships [24, 25], and may provide differing levels of taxonomic resolution and differing perspectives on organismal history $[25,33,49]$. The results of separate analyses using each of the 5 genetic loci are shown in Fig. 2. A tree based on a comparative analysis of $16 \mathrm{~S}$ rRNA sequences from a similar set of organisms is provided for comparison. The ATPase sequences of the Chlamydia and Thermus/Deinococcus phyla, and the RNase P RNA sequences of low $\mathrm{G}+\mathrm{C}$ Gram-positives could not be included because they represent different (non-homologous) molecule types (V-type ATPases, type B RNAase P RNAs).

In all of these analyses the class Actinobacteria was monophyletic. T. whipplei was placed within this class in all cases, and by each of the phylogenetic algorithms. These findings confirm previous assignments based on 16S rRNA [26, 32, 48], 5S and 23S rRNA [28], and RpoB [6] analyses. Closest relatives of T. whipplei in the different trees were Nocardioides jenseni (rnpB), Propionibacterium acnes (GroEL), Micrococcus luteus (Tuf), and $S$. coelicolor (AtpD and RpoB); however, in contrast with $16 \mathrm{~S}$ rDNA-based analysis [26], a fine resolution picture of relationships within the Actinobacteria is not possible with these alternative genetic loci, due to the much smaller number of available sequences. The branching orders at the level of different bacterial phyla varied between analyses and treeing algorithms. This is in accordance with the conclusions of previous assessments of bacterial phylogeny $[17,23,37]$. RNase P RNA is a smaller and much more variable molecule than the other markers, but it has been used to resolve differences within narrow taxonomic ranges, such as within LL-2,6-diaminopimelic acid-containing actinomycetes [49] and Chlamydia spp. [14]. As expected from its large size, the most stable tree topology was achieved with RpoB.

The GroEL tree (Fig. 2C) revealed different groupings for the known GroEL1 and GroEL2 proteins of mycobacteria, corynebacteria, and streptomycetes; the T. whipp$l e i$ sequence was clearly more similar to the GroEL2, than the GroEL1, proteins of other actinobacteria. To check for a possible sequence chimera, the two halves of T. whipplei GroEL sequence were analyzed separately; both were more similar to GroEL2 sequences. Different phylogenetic groupings of GroEL1 and GroEL2 sequences for the actinobacteria have been noted previously $[18,43]$. GroEL1 proteins appear to be subject to fewer selective or functional constraints and evolve faster than GroEL2 proteins. This is reflected by the larger evolutionary distances within the GroEL1 group in Figure 2C. Assuming a groEL gene duplication event during the evo- 


\section{A. AtpD}

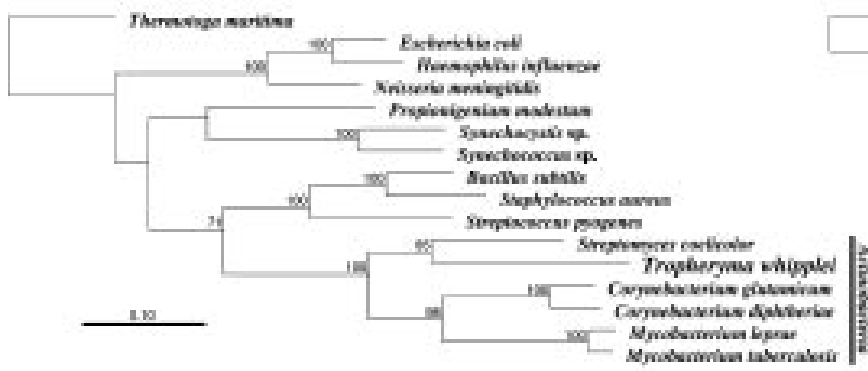

\section{GroEL}

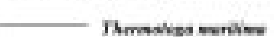

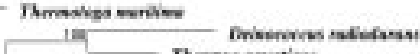

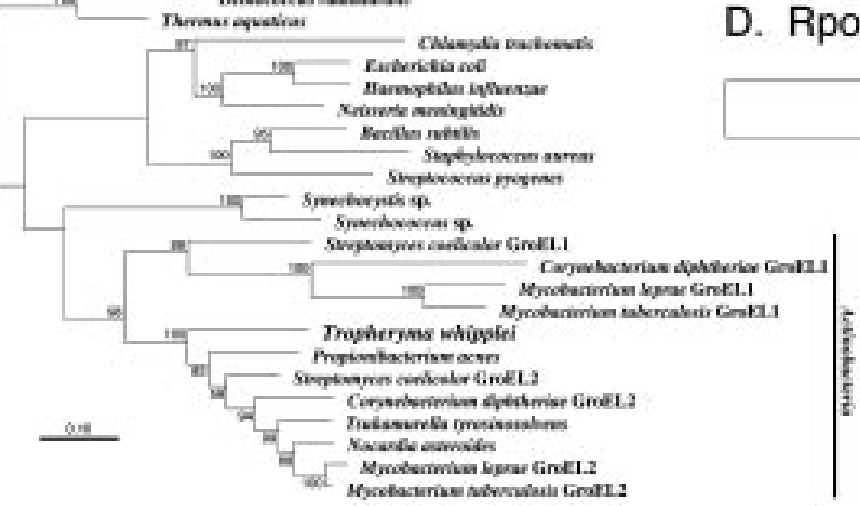

B. Tuf

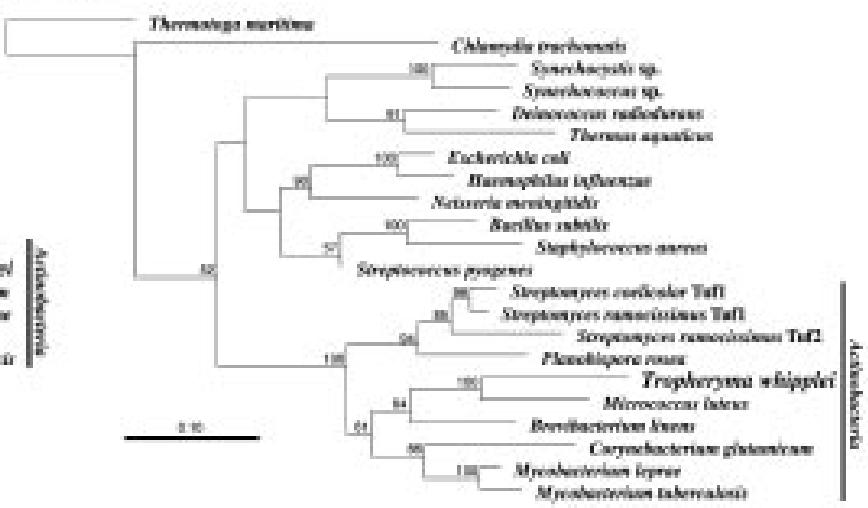

\section{F. $16 \mathrm{~S}$ rRNA}

\section{E. RNase P RNA}
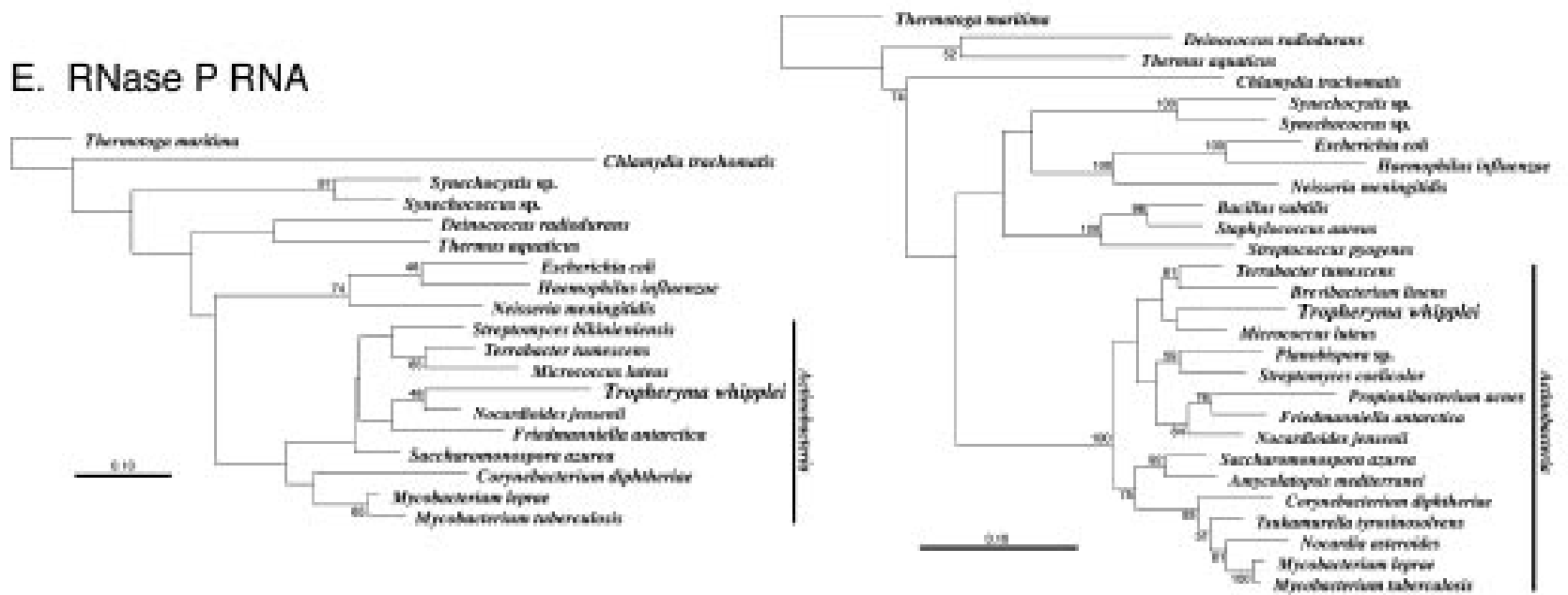

Fig. 2. Phylogenetic analyses. (A) ATP synthase beta subunit protein; (B) Elongation factor Tu protein; (C) GroEL protein; (D) RpoB protein; (E) RNase P RNA; (F) 16S rRNA. The trees in this figure were calculated using Maximum Likelihood algorithms and evaluated by bootstrap analysis with 100 re-samplings. The scale bar indicates 0.1 amino acid or nucleotide substitutions per position, and bootstrap values $\geq 50 \%$ are indicated. The phylum Actinobacteria is monophyletic in each tree and is marked by a vertical bar. 
lution of the Actinobacteria, the absence of the groESlinked groEL1 allele in the T. whipplei genome suggests subsequent gene loss during the evolutionary history of this organism.

\section{Variable numbers of tandem repeats (VNTRs)}

A total of 4 repeat-sequence motifs were found in the 7 T. whipplei chromosomal regions, including one homopolymeric G-tract and three tandem repeat sequences. The tandem repeats were located in the GroEL chromosomal region (21-mer: TTTATGTCATTCTCTTGCAGA), and upstream and downstream of the rRNA operon (upstream, 14-mer: AACTGWTACTGAGT; downstream, 9-mer: GTTCTAGTA). In order to explore their suitability for strain typing, these regions were amplified and sequenced from tissue samples of 10 additional Whipple's disease patients. The results are provided in Table 3, together with the results of 16S-23S rRNA intergenic spacer typing. Within this specimen/strain collection, there were 1 or 2 copies at the GroEL VNTR locus, 1-3 in the rRNA operon upstream VNTR locus, and 3-8 at the rRNA operon downstream VNTR locus. Each $T$. whipplei strain had a unique combination of rRNA spacer type and VNTR locus repeat numbers. Although not examined in detail, variation in the poly-G-tract was also observed; the biopsy of the index patient in this study had $11 \mathrm{Gs}$, and previously examined biopsies had 8 and 10 Gs, respectively [28].

Sequence repeats are prone to slipped-strand mispairing during DNA replication, which leads to frequent insertion and deletion of repeat units. This phenomenon leads to the emergence of strain-specific differences, and also provides a mechanism for genetic adaptation to different environments [11, 40,41], such as might be required if T. whipplei transits from an external environmental niche to the human intestinal tract [27]. Repeatsequence switching is a common mechanism of bacterial phase variation, and can affect genes relevant to antigenicity or pathogenicity [11]. VNTR-based typing has proven useful in the analysis of Bacillus anthracis population structure [20]. Multiple-locus VNTR analysis has high discriminatory power and has revealed distinct geographic clustering of $B$. anthracis strains, despite the relatively invariant nature of the $B$. anthracis genome. Our results indicate high discriminatory power of VNTR analysis for T. whipplei. Further studies will be needed to determine the usefulness of a VNTR typing system for $T$. whipplei; questions arise as to which of the VNTR loci are stable in distinct strains of T. whipplei, and which are subject to variation during the course of the disease or during propagation of the organism in vitro.

\section{Conclusions}

The sequences determined in this study, comprising a total of 13,193 bp, were extracted directly from a relevant naturally-infected site, using a single paraffin-embedded intestinal biopsy specimen in which T. whipplei was particularly abundant. This genomic information will soon be greatly extended with the completion and analysis of a full genome sequence (http://www.sanger.ac.uk/Projects/ T_whippelii/) from a different strain. Among the findings from our data, all phylogenetic analyses using five nonrRNA data sets confirmed the position of T. whipplei within the phylum, Actinobacteria. The organization of the T. whipplei atpD, groEL, and rpoB chromosomal regions was consistent with other actinobacteria genomes. The discovery of VNTR loci may provide the basis for a new T. whipplei strain typing scheme with high discriminatory power. This method awaits further evaluation as a source of new insight into the pathogenesis, epidemiology and transmission of Whipple's disease.

\section{Acknowledgements}

This work was supported by a grant from the Deutsche Forschungsgemeinschaft (Ma 1663/3-1), a Dean's Fellowship from Stanford University to M.M., NIH Digestive Disease

Table 3. Results of rRNA intergenic spacer typing and VNTRs in the GroEL and rRNA operon upstream and downstream chromosomal regions for different T. whipplei strains.

\begin{tabular}{clllll}
\hline Patient & Sample & rRNA spacer type & GroEL contig & rRNA operon upstream ${ }^{\mathrm{c}}$ rRNA operon downstream $^{\mathrm{c}}$ \\
\hline $1^{\mathrm{a}}$ & IB $^{\mathrm{b}}$ & 2 & $2 \times$ & $2 \times$ & $6 \times$ \\
2 & IB & 1 & $1 \times$ & $1 \times$ & $4 \times$ \\
3 & IB & 1 & $1 \times$ & $2 \times$ & $4 \times$ \\
4 & CSF & 1 & $1 \times$ & $3 \times$ & $5 \times$ \\
5 & IB & 1 & $1 \times$ & $3 \times$ & $6 \times$ \\
6 & IB & 2 & $1 \times$ & $2 \times$ & $7 \times$ \\
7 & CSF & 2 & $1 \times$ & $2 \times$ & $8 \times$ \\
8 & CSF & 2 & $1 \times$ & $3 \times$ & $5 \times$ \\
9 & CSF & 2 & $1 \times$ & $2 \times$ & $3 \times$ \\
10 & CSF & 2 & $2 \times$ & $2 \times$ & $8 \times$ \\
11 & IB & 2 & $2 \times$ & & \\
\hline
\end{tabular}

a This is the index patient whose sample was used to assemble the chromosomal region sequences in this study.

b IB, intestinal biopsy.

c The number of repeats is given. 
Research Center grant DK56339 (M.M., D.A.R.), and by grants from the Donald E. and Delia B. Baxter Foundation and the Wellcome Trust/Beowulf Genomics (ME019238) to D.A.R. We thank A. von Herbay (University of Heidelberg, Germany) for providing patient specimens and histopathological information, C. A. Cummings (Stanford University) for advice regarding sequence analysis, J. W. Brown (North Carolina State University) for determining the secondary structure of the RNase P RNA as well as providing valuable information regarding the RNase $P$ RNA database, and L. Brocchieri (Stanford University) for advice regarding protein sequence alignments.

\section{References}

1. Brocchieri, L., Karlin, S.: A symmetric-iterated multiple alignment of protein sequences. J. Mol. Biol. 276, 249-264 (1998).

2. Brocchieri, L., Karlin, S.: Conservation among HSP60 sequences in relation to structure, function, and evolution. Protein Sci. 9, 476-486 (2000).

3. Brown, J. W.: The Ribonuclease P Database. Nucleic Acids Res. 27, 314 (1999).

4. Cole, S. T., Brosch, R., Parkhill, J., Garnier, T., Churcher, C., Harris, D., Gordon, S. V., Eiglmeier, K., Gas, S., Barry, C. E., 3rd, Tekaia, F., Badcock, K., Basham, D., Brown, D., Chillingworth, T., Connor, R., Davies, R., Devlin, K., Feltwell, T., Gentles, S., Hamlin, N., Holroyd, S., Hornsby, T., Jagels, K., Barrell, B. G., et al.: Deciphering the biology of Mycobacterium tuberculosis from the complete genome sequence. Nature 393, 537-544 (1998).

5. Cole, S. T., Eiglmeier, K., Parkhill, J., James, K. D., Thomson, N. R., Wheeler, P. R., Honore, N., Garnier, T., Churcher, C., Harris, D., Mungall, K., Basham, D., Brown, D., Chillingworth, T., Connor, R., Davies, R. M., Devlin, K., Duthoy, S., Feltwell, T., Fraser, A., Hamlin, N., Holroyd, S., Hornsby, T., Jagels, K., Lacroix, C., Maclean, J., Moule, S., Murphy, L., Oliver, K., Quail, M. A., Rajandream, M. A., Rutherford, K. M., Rutter, S., Seeger, K., Simon, S., Simmonds, M., Skelton, J., Squares, R., Squares, S., Stevens, K., Taylor, K., Whitehead, S., Woodward, J. R., Barrell, B. G.: Massive gene decay in the leprosy bacillus. Nature 409, 1007-1011 (2001).

6. Drancourt, M., Carlioz, A., Raoult, D.: rpoB sequence analysis of cultured Tropheryma whippelii. J. Clin. Microbiol. 39, 2425-2430 (2001).

7. Felsenstein, J.: PHYLIP (Phylogeny Inference Package) version 3.5c. Department of Genetics, University of Washington, Seattle, Wash. 1993.

8. Geissdörfer, W., Wittmann, I., Rollinghoff, M., Schoerner, C., Bogdan, C.: Detection of a new 16S-23S rRNA spacer sequence variant (type 7) of Tropheryma whippelii in a patient with prosthetic aortic valve endocarditis. Eur. J. Clin. Microbiol. Infect. Dis. 20, 762-763 (2001).

9. Haas, E. S., Banta, A. B., Harris, J. K., Pace, N. R., Brown, J. W.: Structure and evolution of ribonuclease P RNA in Grampositive bacteria. Nucleic Acids Res. 24, 4775-4782 (1996).

10. Hecker, M., Schumann, W., Völker, U.: Heat-shock and general stress response in Bacillus subtilis. Mol. Microbiol. 19, 417-428 (1996).

11. Henderson, I. R., Owen, P., Nataro, J. P.: Molecular switches - the $\mathrm{ON}$ and OFF of bacterial phase variation. Mol. Microbiol. 33, 919-932 (1999).

12. Henikoff, S., Henikoff, J. G.: Protein family classification based on searching a database of blocks. Genomics 19, 97-107 (1994).
13. Hensel, M., Lill, H., Schmid, R., Deckers-Hebestreit, G., Altendorf, K.: The ATP synthase (F1F0) of Streptomyces lividans: sequencing of the atp operon and phylogenetic considerations with subunit beta. Gene 152, 11-17 (1995).

14. Herrmann, B., Winqvist, O., Mattsson, J. G., Kirsebom, L. A.: Differentiation of Chlamydia spp. by sequence determination and restriction endonuclease cleavage of RNase P RNA genes. J. Clin. Microbiol. 34, 1897-1902 (1996).

15. Hinrikson, H. P., Dutly, F., Nair, S., Altwegg, M.: Detection of three different types of 'Tropheryma whippelii' directly from clinical specimens by sequencing, single-strand conformation polymorphism (SSCP) analysis and type-specific PCR of their 16S-23S ribosomal intergenic spacer region. Int. J. Syst. Bacteriol. 49, 1701-1706 (1999).

16. Hoogvliet, G., van Wezel, G. P., Kraal, B.: Evidence that a single EF-Ts suffices for the recycling of multiple and divergent EF-Tu species in Streptomyces coelicolor A3(2) and Streptomyces ramocissimus. Microbiology 145, 2293-2301 (1999).

17. Hugenholtz, P., Goebel, B. M., Pace, N. R.: Impact of culture-independent studies on the emerging phylogenetic view of bacterial diversity. J. Bacteriol. 180, 4765-4774 (1998).

18. Hughes, A. L.: Contrasting evolutionary rates in the duplicate chaperonin genes of Mycobacterium tuberculosis and M. leprae. Mol. Biol. Evol. 10, 1343-1359 (1993).

19. Karlin, S., Mrazek, J., Campbell, A., Kaiser, D.: Characterizations of highly expressed genes of four fast-growing bacteria. J. Bacteriol. 183, 5025-5040 (2001).

20. Keim, P., Price, L. B., Klevytska, A. M., Smith, K. L., Schupp, J. M., Okinaka, R., Jackson, P. J., Hugh-Jones, M. E.: Multiple-locus variable-number tandem repeat analysis reveals genetic relationships within Bacillus anthracis. J. Bacteriol. 182, 2928-2936 (2000).

21. Klenk, H. P., Zillig, W.: DNA-dependent RNA polymerase subunit $\mathrm{B}$ as a tool for phylogenetic reconstructions: branching topology of the archaeal domain. J. Mol. Evol. 38, 420-432 (1994).

22. La Scola, B., Fenollar, F., Fournier, P. E., Altwegg, M., Mallet, M. N., Raoult, D.: Description of Tropheryma whipplei gen. nov., sp. nov., the Whipple's disease bacillus. Int. J. Syst. Evol. Microbiol. 51, 1471-1479 (2001).

23. Ludwig, W., Neumaier, J., Klugbauer, N., Brockmann, E., Roller, C., Jilg, S., Reetz, K., Schachtner, I., Ludvigsen, A., Bachleitner, M., Fischer, U., Schleifer, K. H.: Phylogenetic relationships of Bacteria based on comparative sequence analysis of elongation factor Tu and ATP-synthase beta-subunit genes. Antonie Van Leeuwenhoek 64, 285-305 (1993).

24. Ludwig, W., Schleifer, K. H.: Bacterial phylogeny based on $16 \mathrm{~S}$ and $23 \mathrm{~S}$ rRNA sequence analysis. FEMS Microbiol. Rev. 15, 155-173 (1994).

25. Ludwig, W., Strunk, O., Klugbauer, S., Klugbauer, N., Weizenegger, M., Neumaier, J., Bachleitner, M., Schleifer, K. H.: Bacterial phylogeny based on comparative sequence analysis. Electrophoresis 19, 554-568 (1998).

26. Maiwald, M., Ditton, H. J., von Herbay, A., Rainey, F. A., Stackebrandt, E.: Reassessment of the phylogenetic position of the bacterium associated with Whipple's disease and determination of the $16 \mathrm{~S}-23 \mathrm{~S}$ ribosomal intergenic spacer sequence. Int. J. Syst. Bacteriol. 46, 1078-1082 (1996).

27. Maiwald, M., Schuhmacher, F., Ditton, H. J., von Herbay, A.: Environmental occurrence of the Whipple's disease bacterium (Tropheryma whippelii). Appl. Environ. Microbiol. 64, 760-762 (1998).

28. Maiwald, M., von Herbay, A., Lepp, P. W., Relman, D. A.: Organization, structure, and variability of the rRNA operon of the Whipple's disease bacterium (Tropheryma whippelii). J. Bacteriol. 182, 3292-3297 (2000). 
29. Morgenegg, S., Dutly, F., Altwegg, M.: Cloning and sequencing of a part of the heat shock protein 65 gene (hsp65) of "Tropheryma whippelii" and its use for detection of "T. whippelii" in clinical specimens by PCR. J. Clin. Microbiol. 38, 2248-2253 (2000).

30. Raoult, D., Birg, M. L., La Scola, B., Fournier, P. E., Enea, M., Lepidi, H., Roux, V., Piette, J. C., Vandenesch, F., VitalDurand, D., Marrie, T. J.: Cultivation of the bacillus of Whipple's disease. N. Engl. J. Med. 342, 620-625 (2000).

31. Redenbach, M., Kieser, H. M., Denapaite, D., Eichner, A., Cullum, J., Kinashi, H., Hopwood, D. A.: A set of ordered cosmids and a detailed genetic and physical map for the 8 Mb Streptomyces coelicolor A3(2) chromosome. Mol. Microbiol. 21, 77-96 (1996).

32. Relman, D. A., Schmidt, T. M., Macdermott, R. P., Falkow, S.: Identification of the uncultured bacillus of Whipple's Disease. N. Engl. J. Med. 327, 293-301 (1992).

33. Renesto, P., Gautheret, D., Drancourt, M., Raoult, D.: Determination of the $r p o B$ gene sequences of Bartonella henselae and Bartonella quintana for phylogenic analysis. Res. Microbiol. 151, 831-836 (2000).

34. Rinke de Wit, T. F., Bekelie, S., Osland, A., Miko, T. L. Hermans, P. W., van Soolingen, D., Drijfhout, J. W., Schoningh, R., Janson, A. A., Thole, J. E.: Mycobacteria contain two groEL genes: the second Mycobacterium leprae groEL gene is arranged in an operon with groES. Mol. Microbiol. 6, 1995-2007 (1992).

35. Saraste, M., Sibbald, P. R., Wittinghofer, A.: The P-loop - a common motif in ATP- and GTP-binding proteins. Trends Biochem. Sci. 15, 430-434 (1990).

36. Sarkar, G., Turner, R. T., Bolander, M. E.: Restriction-site PCR: a direct method of unknown sequence retrieval adjacent to a known locus by using universal primers. PCR Methods Appl. 2, 318-322 (1993).

37. Schmidt, T. M., DeLong, E. F., Pace, N. R.: Analysis of a marine picoplankton community by $16 \mathrm{~S}$ rRNA gene cloning and sequencing. J. Bacteriol. 173, 4371-4378 (1991).

38. Sela, S., Yogev, D., Razin, S., Bercovier, H.: Duplication of the $t u f$ gene: a new insight into the phylogeny of eubacteria. J. Bacteriol. 171, 581-584 (1989).

39. Strunk, O., Gross, O., Reichel, B., May, M., Hermann, S., Stuckmann, N., Nonhoff, B., Ginhart, T., Vilbig, A., Lenke, M., Ludwig, T., Bode, A., Schleifer, K.-H., Ludwig, W. ARB: a software environment for sequence data. Department of Microbiology, Technische Universität München, Munich, Germany. 1999.
40. van Belkum, A., Scherer, S., van Alphen, L., Verbrugh, H.: Short-sequence DNA repeats in prokaryotic genomes. Microbiol. Mol. Biol. Rev. 62, 275-293 (1998).

41. van Belkum, A.: The role of short sequence repeats in epidemiologic typing. Curr. Opin. Microbiol. 2, 306-311 (1999).

42. van Wezel, G. P., Woudt, L. P., Vervenne, R., Verdurmen, M. L., Vijgenboom, E., Bosch, L.: Cloning and sequencing of the tuf genes of Streptomyces coelicolor A3(2). Biochim. Biophys. Acta 1219, 543-547 (1994).

43. Viale, A. M., Arakaki, A. K., Soncini, F. C., Ferreyra, R. G.: Evolutionary relationships among eubacterial groups as inferred from GroEL (chaperonin) sequence comparisons. Int. J. Syst. Bacteriol. 44, 527-533 (1994).

44. Vijgenboom, E., Woudt, L. P., Heinstra, P. W., Rietveld, K., van Haarlem, J., van Wezel, G. P., Shochat, S., Bosch, L.: Three tuf-like genes in the kirromycin producer Streptomyces ramocissimus. Microbiology 140, 983-998 (1994).

45. von Herbay, A., Ditton, H. J., Maiwald, M.: Diagnostic application of a polymerase chain reaction assay for the Whipple's disease bacterium to intestinal biopsies. Gastroenterology 110, 1735-1743 (1996).

46. von Herbay, A., Ditton, H. J., Schuhmacher, F., Maiwald, M.: Whipple's disease: Staging and monitoring by cytology and polymerase chain reaction analysis of cerebrospinal fluid. Gastroenterology 113, 434-441 (1997).

47. Walker, J. E., Saraste, M., Runswick, M. J., Gay, N. J.: Distantly related sequences in the alpha- and beta-subunits of ATP synthase, myosin, kinases and other ATP-requiring enzymes and a common nucleotide binding fold. EMBO J. 1, 945-951 (1982).

48. Wilson, K. H., Blitchington, R., Frothingham, R., Wilson, J. A. P.: Phylogeny of the Whipple's disease-associated bacterium. Lancet 338, 474-475 (1991).

49. Yoon, J. H., Park, Y. H.: Comparative sequence analyses of the ribonuclease $\mathrm{P}$ (RNase P) RNA genes from LL-2,6diaminopimelic acid-containing actinomycetes. Int. J. Syst. Evol. Microbiol. 50, 2021-2029 (2000).

\section{Corresponding author:}

David A. Relman, VA Palo Alto Health Care System 154T, 3801

Miranda Avenue, Palo Alto, CA 94304, USA

Tel.: ++1 (650) 852-3308; Fax: ++1 (650) 852-3291;

e-mail: relman@stanford.edu 